\title{
CIRCULACIÓN MACRO-REGIONAL DE ESPECIES VEGETALES SILVESTRES: EL CASO DE CUEVA YAGUI (NEUQUÉN, ARGENTINA)
}

\section{MACRO-REGIONAL CONVEYANCE OF WILD VEGETAL SPECIES: A CASE STUDY FROM CUEVA YAGUI (NEUQUÉN, ARGENTINA)}

\author{
Clara Sánchez Campóoㄹ, Ramiro Barberena², Guadalupe Romero Villanueva ${ }^{3}$, \\ Carina Llano ${ }^{4}$
}

${ }^{1}$ Consejo Nacional de Investigaciones Científicas y Técnicas (CONICET). Laboratorio de Etnobotánica Aplicada (LEA), Facultad de Ciencias Aplicadas a la Industria. Universidad Nacional de Cuyo. Bernardo de Yrigoyen 375 (5600), Mendoza, Argentina.

Email: mclaracampoo@gmail.com

${ }^{2}$ Consejo Nacional de Investigaciones Científicas y Técnicas (CONICET). Instituto Interdisciplinario de Ciencias Básicas (ICB), Laboratorio Paleoecología Humana, Facultad de Ciencias Exactas y Naturales. Facultad de Filosofía y Letras, Universidad Nacional de Cuyo.

Padre Jorge Contreras 1300 (5500), Mendoza, Argentina. Email: rbarberena@mendoza-conicet.gob.ar

${ }^{3}$ Consejo Nacional de Investigaciones Científicas y Técnicas (CONICET), Instituto Nacional de Antropología y Pensamiento Latinoamericano. 3 de febrero 1378, Ciudad Autónoma de Buenos

Aires, Argentina. Email: gromerovillanueva@conicet.gov.ar

${ }^{4}$ Consejo Nacional de Investigaciones Científicas y Técnicas (CONICET). Laboratorio de Etnobotánica Aplicada (LEA), Facultad de Ciencias Aplicadas a la Industria. Universidad Nacional de Cuyo. Bernardo de Yrigoyen 375 (5600), Mendoza, Argentina.

Email: $\underline{\text { lano.carina@gmail.com }}$

Presentado: $14 / 06 / 2020$

Aceptado: 19/03/2021

\section{Resumen}

En el presente trabajo se analiza el aprovisionamiento de recursos vegetales implementado durante el Holoceno por los grupos móviles del norte del Neuquén (Patagonia). Se toma como caso de estudio al sitio Cueva Yagui, cuyas ocupaciones humanas fueron datadas entre los 8500 y 1800 años cal AP. Durante este lapso, el registro arqueológico recuperado en estratigrafía y superficie, así como el arte rupestre allí documentado, evidencia que este espacio fue ocupado en forma redundante e intensa para la realización de múltiples actividades, con mayor énfasis en el Holoceno tardío. La metodología de recuperación del registro botánico fue la flotación manual que propició la recuperación de macrorrestos. Del total del material botánico examinado se reconocieron dos especies: Sarcomphalus mistol (sinónimo de Ziziphus mistol) (ca. 98 \%) y Schinus polygamus. Estos datos son discutidos en el marco de las estrategias de subsistencia, movilidad y circulación de información implementadas por los grupos humanos bajo estudio, en distintas escalas espaciales y a lo largo del poblamiento del norte del Neuquén. En este contexto, el alto predominio de una especie alóctona (mistol), invita a reflexionar 
sobre la necesidad de flexibilizar los modelos de aproximación al estudio de la movilidad y subsistencia del Holoceno tardio en Patagonia. Con ello se busca aportar a una comprensión más profunda de las distintas formas de adquisición de los recursos que permitieron ampliar la subsistencia, junto con el uso diversificado y estacional del paisaje.

Palabras clave: Arqueobotánica, Patagonia, recursos alóctonos, mistol

\begin{abstract}
This paper presents an analysis of plant resource procurement by prehistoric huntersgatherers of northern Neuquén (Argentine Patagonia). Using the Cueva Yagui archaeological site as a case study, we assess regional strategies of subsistence, mobility, and the circulation of information at different spatial scales. Cueva Yagui occupations date to between 8500 and 1800 cal BP, during which period the material record indicates that the site was used redundantly and intensively for multiple activities. To recover botanical materials we used manual flotation, which yielded not only plant macroremains but also large amounts of bone. Among the examined materials, two species were recognized: Sarcomphalus mistol (synonym of Ziziphus mistol) (ca. $98 \%$ ) and Schinus polygamus. In this context, the near-exclusive dominance of a non-local species invites us to reflect on the need to consider multiple models in our studies of regional mobility and subsistence during the late Holocene, as we attempt to understand the different forms of resource acquisition including a flexible diet and a diversified, seasonal use of the landscape.
\end{abstract}

Keywords: archaeobotany, Patagonia, foreign taxa, mistol

\title{
Introducción
}

El estudio sistemático de los restos vegetales recuperados en contextos arqueológicos ha conducido a la reevaluación de múltiples temas centrales sobre su aprovechamiento por parte de las sociedades móviles. Algunas de las problemáticas discutidas incluyen la existencia de dietas amplias que integran el consumo de recursos con alto costo de procesamiento (Crittenden y Schnorr 2017; Figueroa y Dantas 2006; Llano 2015; Llano y Ugan 2010), la incorporación de especies domésticas, ya sea con fines económicos, tecnológicos o sociales (Lagiglia 1999; Roa et al. 2018), y la circulación de especímenes en escalas geográficas macrorregionales que no pueden ser explicadas por su rendimiento económico (Belmar et al. 2017; Capparelli y Prates 2010). Sobre esta base, en este trabajo se aborda la explotación y los usos de los recursos vegetales por grupos humanos móviles del norte de Patagonia, con énfasis en el análisis de temas vinculados con la amplitud dietaria y la escala espacial de la organización de la movilidad y las interacciones sociales. 
Para ello, se parte del estudio arqueobotánico del sitio Cueva Yagui, ubicado en el noroeste de Patagonia (Departamento Pehuenches, Provincia del Neuquén, Argentina) (Figura 1). Se entiende que desde un enfoque arqueobotánico es posible verificar qué ambientes se explotaron en forma sistemática, a partir de los taxones locales identificados, así como también discutir patrones macrorregionales de interacción sobre la base de la presencia de taxones no locales, que podrían haber sido obtenidos en forma indirecta o por mecanismos distintos a la circulación cotidiana dentro de los rangos de acción (Pallo y Borrero 2015; Whallon 2006).

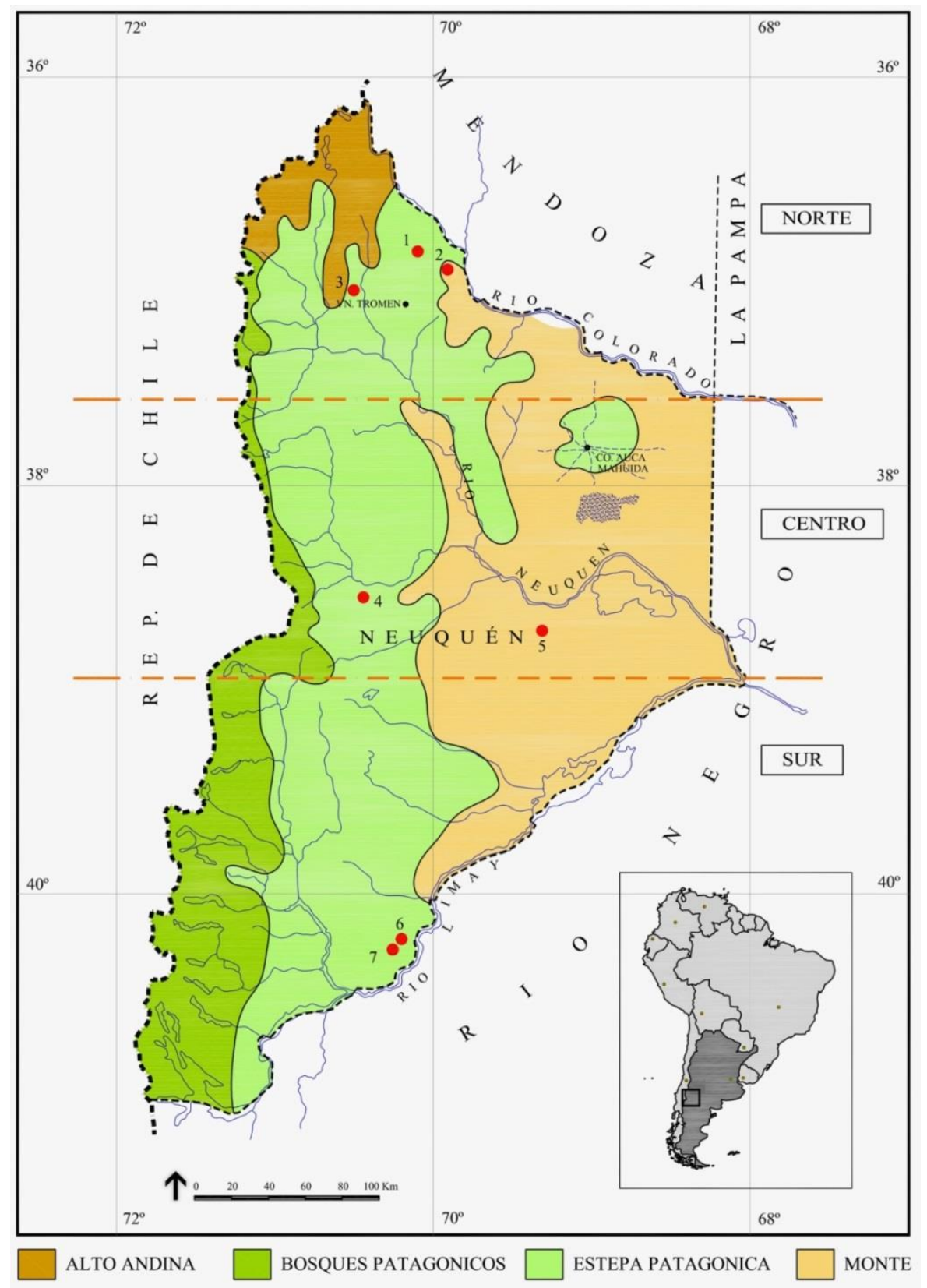

Figura 1. Ubicación de Cueva Yagui, dentro de la Localidad Barrancas-Buta Ranquil, y de otros sitios arqueológicos con estudios arqueobotánicos del Neuquén (Patagonia, Argentina).

Referencias: $1=$ Cueva Yagui; $2=$ Cueva Huenul 1; $3=$ Aquihuecó; $4=$ Cueva Haichol; $5=$ Michacheo; 6 = Epullán Chica; 7 = Epullán Grande. Para bibliografía de base ver Tabla 1 . 
El sitio Cueva Yagui fue excavado en el año 2015 en el marco de un proyecto regional enfocado en la Localidad Barrancas-Buta Ranquil (de aquí en más LBB), ubicada en el norte del Neuquén. Los objetivos del proyecto son estudiar las formas de organización espacial humana desde una perspectiva biogeográfica en relación con la estructura del paisaje del noroeste de Patagonia (Barberena et al. 2017; Llano et al. 2019, 2020; Romero Villanueva 2019; Romero Villanueva et al. 2020a, 2020b; Rughini et al. 2020). El enfoque se centra en el análisis espacial y temporal de las pautas de conducta de las poblaciones a través de conceptos y herramientas teórico-metodológicas que permiten integrar información generada por diversas líneas de evidencia arqueológicas. De esta manera, es posible comprender la relación de los organismos con las propiedades del paisaje que habitan y sus cambios en el tiempo (Lahr y Foley 1998).

En particular, el presente estudio de escala local permite ahondar en las formas de aprovechamiento de los recursos vegetales en el marco de las demás estrategias de subsistencia, movilidad y circulación de información implementadas por los grupos humanos en la región de estudio. Sumado a ello, su integración con otros registros arqueobotánicos conocidos para Patagonia, permite incorporar evidencia con sólida información contextual al debate sobre el transporte de taxones vegetales silvestres a grandes distancias. Con ello, se busca obtener una comprensión más amplia del rol de estos recursos en las redes humanas macrorregionales de movilidad, interacción social y circulación de bienes e información.

\section{Antecedentes sobre el registro arqueobotánico del Neuquén}

Si bien se cuenta con un cúmulo importante de información arqueológica sobre el poblamiento del Neuquén, no todos los sitios evidencian el uso de plantas (Cúneo et al. 2016; Della Negra et al. 2014; Gordón et al. 2017 Hajduk et al. 2011; entre otros). Las razones pueden ser múltiples y abarcan desde su ausencia material, ya sea por causas antrópicas o tafonómicas, hasta la implementación de métodos de excavación no conducentes a una recuperación eficaz de restos macrobotánicos (Pearsall 2000). No obstante, las publicaciones arqueobotánicas en Patagonia y regiones cercanas han experimentado un sutil aumento en los últimos años, denotando la complementariedad de este tipo de registro con las demás líneas que se integran en el análisis arqueológico (Caruso Fermé 2018; Ciampagna 2015; Ciampagna y Mange 2017; Lema et al. 2012; Llano y Andreoni 2012; Musaubach y Berón 2016; entre otros). A modo de síntesis, en la Figura 1 y Tabla 1 se presentan los sitios arqueológicos del Neuquén que registran análisis macro y microbotánico evidenciando las formas de interacción entre las sociedades humanas y las plantas. 


\begin{tabular}{|c|c|c|c|c|c|}
\hline \multirow[t]{2}{*}{ Sitio } & \multirow{2}{*}{$\begin{array}{l}\text { Microrrestos } \\
\text { Vegetales }\end{array}$} & \multirow{2}{*}{$\begin{array}{l}\text { Macrorrestos } \\
\text { veget ales }\end{array}$} & \multicolumn{2}{|c|}{ Dataciones } & \multirow[b]{2}{*}{ Referencias } \\
\hline & & & $\begin{array}{c}\text { Fechado } \\
\text { directo }\end{array}$ & $\begin{array}{l}\text { Fechado } \\
\text { contextual }\end{array}$ & \\
\hline \multirow{10}{*}{$\begin{array}{l}\text { Cueva Huenul } \\
1\end{array}$} & \multirow[t]{10}{*}{-} & Retanitla patagonica & $9261 \pm 66$ & \multirow{10}{*}{$\begin{array}{r}\text { ca. } 11.000 \\
\text { a } 400 \mathrm{AP}\end{array}$} & \multirow{10}{*}{$\begin{array}{l}\text { Llano et al 2019; Llano y Barberena } \\
\text { 2013; Sosa } 2016\end{array}$} \\
\hline & & Senna aphytla & $4786 \pm 46$ & & \\
\hline & & Schimus polygamus & & & \\
\hline & & Chuquiraga oppositifotia & & & \\
\hline & & Eruca vesicaria & & & \\
\hline & & Maihuen iopsis darwini & & & \\
\hline & & Atriplex lampa & & & \\
\hline & & Larrea divaricata & & & \\
\hline & & Prosopis sp. & $9402 \pm 60$ & & \\
\hline & & Lagenaria sp. & $541 \pm 42$ & & \\
\hline Aquihueco & $\begin{array}{l}\text { Granos de almidón } \\
\text { Prosopis sp. }\end{array}$ & - & & $3700 \mathrm{AP}$ & $\begin{array}{l}\text { Della Negra et at. 2009; Della Negra } \\
\text { y Novellino 2005; Lema et at. } 2012\end{array}$ \\
\hline \multirow[t]{15}{*}{ Cueva Haichol } & \multirow[t]{15}{*}{-} & Chuquea culeou & $1390 \pm 100$ & \multirow[t]{15}{*}{$9000 \mathrm{AP}$} & \multirow{15}{*}{$\begin{array}{l}\text { Fernández y Panare llo 2001; Pérez } \\
\text { de Micou 1988-1990 }\end{array}$} \\
\hline & & Myrtaceae & & & \\
\hline & & Maytenus sp. & & & \\
\hline & & Cyperaceae & & & \\
\hline & & Flotoforia sp. & & & \\
\hline & & Eugeniasp. & & & \\
\hline & & Lagenaria sp. & $225 \pm 85$ & & \\
\hline & & Zea mays & $350 \pm 120$ & & \\
\hline & & Euphorbia sp. & & & \\
\hline & & Cotletia hystrix & & & \\
\hline & & Austrocedrus chilensis & & & \\
\hline & & Oxatis exigua & & & \\
\hline & & Araucaria anaucana & & & \\
\hline & & Embotrium coccineum & & & \\
\hline & & Cortadkina sp. & & & \\
\hline Michacheo & $\begin{array}{l}\text { Granos de almidón } \\
\text { Prosopis sp. y Zea mays }\end{array}$ & & & $1860 \mathrm{AP}$ & Lema et al. 2012 \\
\hline \multirow[t]{7}{*}{ Epullán Chica } & \multirow[t]{7}{*}{ - } & Larrea sp. & & \multirow{7}{*}{$\begin{array}{l}\text { ca. } 2200 \text { a } \\
1500 \mathrm{AP}\end{array}$} & \multirow{7}{*}{ Ciampagna y Mange 2017} \\
\hline & & Schinus sp. & & & \\
\hline & & Adesmia sp. & & & \\
\hline & & Ephedra sp. & & & \\
\hline & & Cotliguaja integerrima & & & \\
\hline & & aff. Chuquiraga erinaceae & & & \\
\hline & & cf. Juncus & & & \\
\hline \multirow{11}{*}{$\begin{array}{l}\text { Epullán } \\
\text { Grande }\end{array}$} & \multirow[t]{11}{*}{ - } & Larrea sp. & & \multirow{11}{*}{$\begin{array}{l}10.000 \quad \mathrm{a} \\
1100 \mathrm{AP}\end{array}$} & \multirow{11}{*}{$\begin{array}{l}\text { Carreras y Nieto 1996; Crivelli } \\
\text { Montero et al. 1996; Rivera y } \\
\text { Fernández 1997-1998 }\end{array}$} \\
\hline & & Cotliguaja integerrima & & & \\
\hline & & Geoffrcea decorticans & & & \\
\hline & & Gucurbita sp. & & & \\
\hline & & Larrea nitida & & & \\
\hline & & Schinus & & & \\
\hline & & Prosopis & & & \\
\hline & & Berberis & & & \\
\hline & & Lycium & & & \\
\hline & & cf. Stipa & & & \\
\hline & & cf. Juncus & & & \\
\hline
\end{tabular}

Tabla 1. Sitios arqueológicos en la provincia del Neuquén estudiados desde una perspectiva arqueobotánica.

Entre los antecedentes regionales generados por nuestro equipo de trabajo se destaca el sitio Cueva Huenul 1, emplazado a 1000 m s.n.m. en un ambiente de Monte (Llano y Barberena 2013; Llano et al. 2019; Sosa 2016) (Figura 1). Su registro arqueobotánico se caracteriza por una gran abundancia y diversidad de macrorrestos vegetales depositados por acción humana, los cuales se encuentran en excelente estado de preservación. Este sitio cuenta con fechados radiocarbónicos para los taxones Prosopis, Retanilla patagonica, Lagenaria y Senna aphylla (Tabla 1). Los macrorrestos 
recuperados corresponden a especies silvestres nativas, las cuales concuerdan con el paisaje regional. Desde el inicio de la secuencia, Prosopis se destaca como el macrorresto más ubicuo, siendo el taxón más abundante en el Holoceno temprano. Hacia el Holoceno tardío, disminuye su intensidad para darle lugar al uso de otros recursos vegetales como Maihueniopsis darwinii. Además, en momentos tardíos se cuenta con la presencia de macrorrestos domesticados como Lagenaria sp. y un cariopse de maíz (Llano y Barberena 2013; Llano et al. 2019).

Entre los antecedentes generados por otros equipos con áreas de investigación en Neuquén, se cuenta con el análisis de microrrestos de especies locales como Prosopis y domesticadas como maíz (Lema et al. 2012). En el sitio Cueva Haichol la preservación de las plantas silvestres y domesticadas en forma de macro y microrrestos evidencian una diversidad de taxones utilizados desde el Holoceno tardío (Pérez de Micou 19881990). Las cuevas Epullán Chica y Epullán Grande registran un uso importante de plantas para el acondicionamiento del espacio o como estructuras de almacenamiento y resaltan el uso de especies no locales recolectadas a más de $80 \mathrm{~km}$ (Ciampagna y Mange 2017; Crivelli Montero et al. 1996). A escala extrarregional, cabe destacar el trabajo de Capparelli y Prates (2010), Gambier (2002) y Cahiza (2007) quienes mencionan la presencia de mistol. Por un lado, Capparelli y Prates (2010) refieren el hallazgo de un único macrorresto de esta especie en el valle del río Negro (Provincia de Río Negro). Por su parte, Gambier (2002) y Cahiza (2007) citan la presencia del fruto de mistol en sitios de la provincia de San Juan. La importancia de su ubicuidad en estos sitios arqueológicos radica en que el mistol corresponde a una especie alóctona a estas zonas lo que permite inferir que fue transportado desde su lugar de origen, tema que se abordará más adelante.

\section{Materiales y métodos}

\section{Descripción del sitio Cueva Yagui}

Cueva Yagui es un abrigo rocoso que se localiza a $1370 \mathrm{~m}$ s.n.m. en la cuenca media del arroyo Buta Có, que es un afluente permanente del río Colorado $\left(36^{\circ} \mathrm{S}, 69^{\circ}\right.$ O) (Figura 1). El contexto paleoambiental para el noroeste de Patagonia fue descripto recientemente en base al análisis de múltiples líneas de evidencia como el polen, los macrorrestos vegetales y los parásitos contenidos en estercoleros fósiles (Llano et al. 2020). Los resultados reflejaron sutiles cambios en la vegetación impulsados por la variabilidad de las precipitaciones relacionadas con los vientos del oeste. En este sentido, en el Holoceno temprano el clima fue más seco y la vegetación refleja un patrón similar al Monte dominada por arbustos altos como Prosopis, Larrea y Lycium, junto con elementos de transición Monte-Patagonia (por ejemplo, Schinus, Ephedra), alcanzando su punto máximo de aridez durante el Holoceno medio. El Holoceno tardío manifestó escenarios más húmedos que los actuales evidenciado por especies de la transición Monte-Patagonia (Llano et al. 2020). En cuanto a la disponibilidad actual de especies, el ambiente donde se emplaza el sitio describe una importante 
heterogeneidad natural (Oyarzábal et al. 2018). Dentro de esta diversidad es posible encontrar, por debajo de los 1100 m s.n.m., una comunidad zonal de estepas arbustivas de Larrea divaricata, acompañada de los géneros Chuquiraga, Prosopis, y Schinus. Por encima de los 1100 m s.n.m., se observa una mezcla de estepa graminosa con baja cobertura de Sporobolus rigens, Panicum urvilleanum y Mulinum spinosum (Figura 2a).

El sitio se encuentra asociado a paredones y bloques con arte rupestre distribuidos a lo largo de más de $35 \mathrm{~m}$ (Figura 2b). Para su estudio, el sitio fue dividido en sectores en relación con su topografía: paredón, cueva y alero (Romero Villanueva et al. 2020b). El área comprendida por el alero es un espacio amplio de $14 \mathrm{~m}$ de largo a plena luz, parcialmente protegido por la proyección de la visera. Adyacente al mismo se inicia una cueva de $23 \mathrm{~m}$ de longitud cuyo piso no presenta fuertes declives y donde la altura del techo no sobrepasa los 1,5 m. En su interior, la circulación se ve interrumpida por varios bloques derrumbados, algunos con motivos rupestres. Por su parte, los paredones basálticos contiguos a la cueva y el alero tienen una altura aproximada entre 4 a $6 \mathrm{~m}$ y se orientan principalmente hacia el norte.

En el sitio se excavó una cuadrícula (C1) de 1 x $1 \mathrm{~m}$ mediante niveles artificiales de extracción de $10 \mathrm{~cm}$ de potencia, los cuales se numeraron a partir de uno desde la superficie hacia la base de la excavación, al tiempo que se diferenciaron unidades estratigráficas naturales y rasgos sedimentarios -antrópicos o naturales- en función de criterios litológicos (ver detalles en Romero Villanueva et al. 2020b). La excavación alcanzó una profundidad máxima de un 1,5 m (desde el 0 artificial ubicado a $4 \mathrm{~cm}$ por sobre la superficie), correspondiendo a 1,4 $\mathrm{m}$ de secuencia estratigráfica y un volumen total de sedimento excavado de $1,4 \mathrm{~m}^{3}$. Así, se excavaron 15 niveles artificiales que fueron posteriormente agrupados en siete unidades lito-estratigráficas.

El sedimento extraído en la excavación fue tamizado en seco en una zaranda con malla de $2 \mathrm{~mm}$ de apertura. Para cada nivel artificial se embolsó en forma completa el volumen de sedimento correspondiente a un balde de excavación entero (5 litros), procedente del sector sudeste de la cuadrícula, el cual fue conservado para su posterior flotación en el laboratorio. Gracias a este procedimiento, fue posible recuperar una muestra arqueobotánica exhaustiva y constante a lo largo de la secuencia de ocupación del sitio. En suma, se flotaron 12 muestras compuestas por $5000 \mathrm{~cm}^{3}$ de sedimento, totalizando $60.000 \mathrm{~cm}^{3}$. El material analizado para el presente artículo se conforma por los macrorrestos provenientes de la flotación ya que no se recuperaron restos vegetales en la zaranda. Dado que la información contextual del sitio se presenta en detalle en otro trabajo (Romero Villanueva et al. 2020b), aquí sólo se retoman algunos datos y tendencias a los fines de enmarcar la discusión del registro arqueobotánico analizado. 


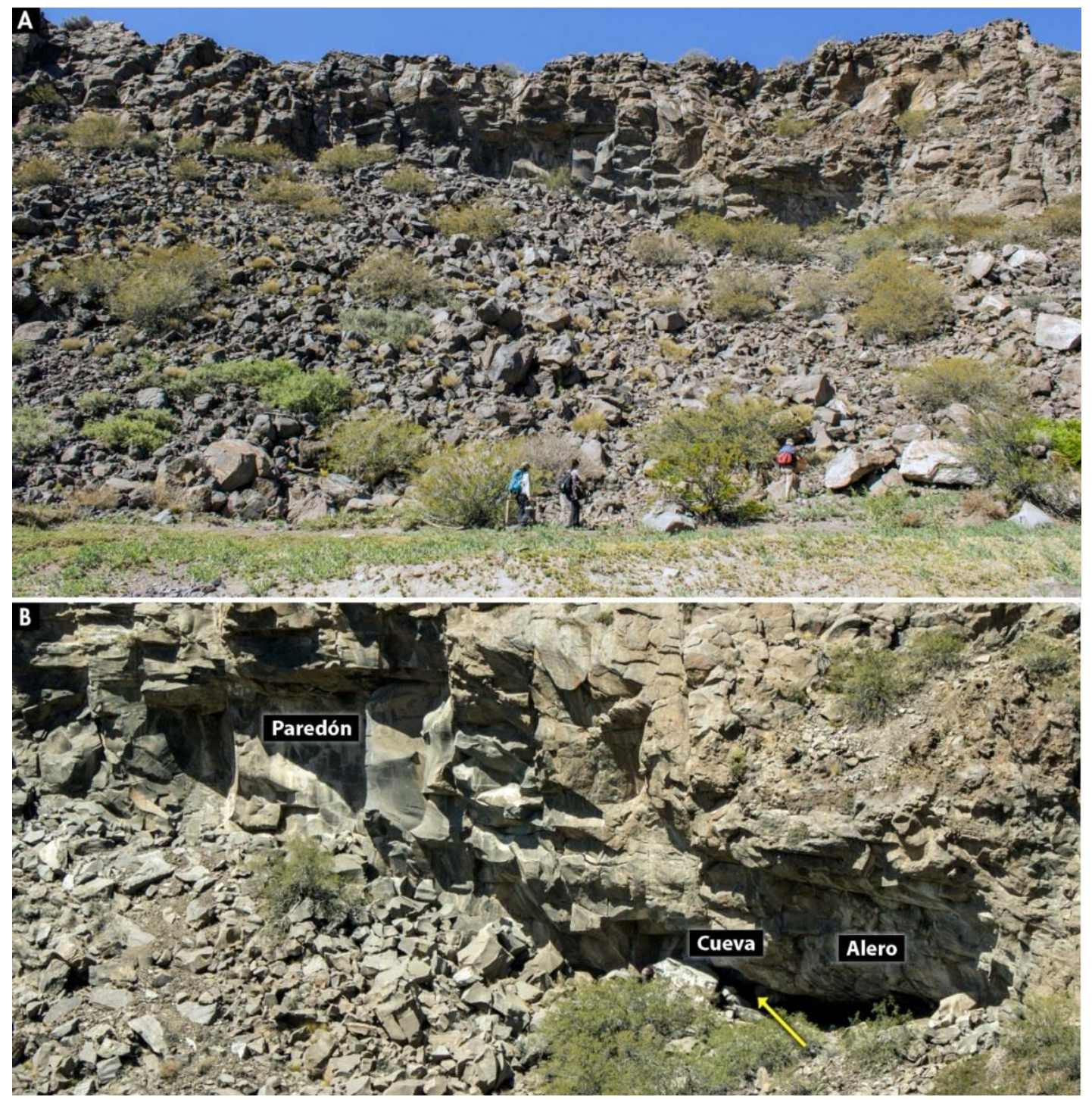

Figura 2. Sitio Cueva Yagui (a) Vista general. (b) Detalle de la cueva

Recuperación e identificación del material arqueobotánico

La recuperación de los restos carpológicos se basó en el procesamiento del sedimento mediante la flotación. Esta técnica consiste en someter una muestra de sedimento a un flujo constante de agua en un recipiente. Este procedimiento permite segregar por densidad y porosidad del material, por un lado, una fracción liviana que flota como los restos vegetales y, por el otro, una fracción pesada que decanta como la cerámica, lítico, óseo, malacológico, etc. Un resultado positivo de la utilización de este método es que reduce el grado de fractura por fricción de los carporrestos (Thomas y Zapata 2018; Wright 2005). Teniendo en cuenta esta premisa, se utilizó una variante en el proceso de flotación, manteniendo el mismo principio, pero con el objetivo de reducir el consumo de agua (Figura 3). De este modo, la secuencia de trabajo consistió en la utilización de dos baldes. En la boca de uno de ellos se coloca una tela de voile de 90 micrones sujetada por medio de broches mientras que se realiza una abertura en la 
base (Figura 3a). En el otro balde, que no presenta modificaciones, se coloca el agua y se añade lentamente el sedimento (Figura 3b). Luego, una vez que decanta el sedimento, el líquido con el material sobrenadante se vuelca en el balde que tiene la tela de voile, tal como se ve en la imagen (Figura 3c). El resultado es una fracción liviana (Figura 3d) y una fracción pesada en cada balde, respectivamente (Figura 3e). Por último, se chequeó en el laboratorio el volumen de sedimento flotado por cada nivel artificial de extracción para llevar un registro de su tamaño y ajustar la estandarización de los resultados.

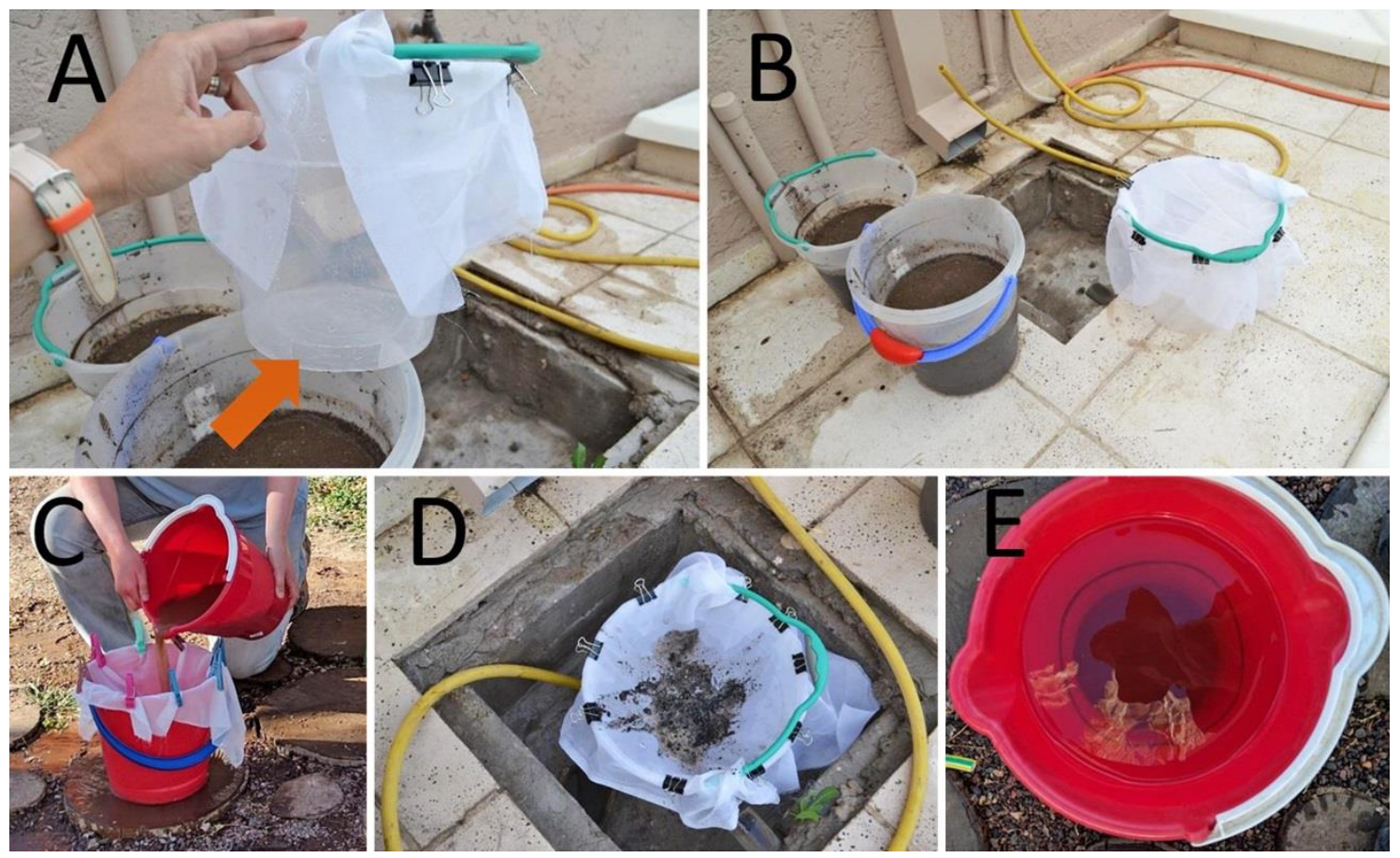

Figura 3. Método de flotación seguido para recuperar el material arqueobotánico.

La discriminación del material macrobotánico de los otros restos contenidos en la fracción liviana se realizó empleando una lupa binocular entre 10x a 20x de aumento. Finalmente, se separaron del conjunto arqueobotánico los macrorrestos enteros (semillas y frutos). Es importante aclarar que, en el caso de frutos fragmentados, se consideró como parte de la muestra a los fragmentos mayores a $1 \mathrm{~cm}$. La etapa de identificación incluyó la revisión de la colección de referencia del área de estudio que está en construcción desde 2011 con el fin de disponer del parámetro comparativo para la identificación taxonómica a través de la anatomía comparada y la observación de la morfología externa (Laboratorio de Etnobotánica Aplicada - FCAI -UNCuyo), como así también la revisión de manuales especializados (Esau 1972; Martin y Barkley 1973). Los macrorrestos fueron contabilizados y se registró su estado de conservación: natural/seco o carbonizado. 


\section{Resultados}

La secuencia de la excavación ha sido estructurada en siete unidades estratigráficas que presentan diferencias en términos de color, textura y estructuras sedimentarias (Romero Villanueva et al. 2020b). Las unidades III a VI (niveles artificiales 7 a 15) se agrupan en el Componente crono-estratigráfico 1 y tienen una cronología del Holoceno medio. Por otra parte, las unidades I y II (niveles artificiales 1 a 6) conforman el Componente 2, separado del anterior por una discordancia erosiva. Se cuenta con un fechado ${ }^{14} \mathrm{C}$ de $1925 \pm 30$ (D-AMS 033196) sobre carbón vegetal procedente de una camada de gramíneas del nivel $3(33-36 \mathrm{~cm})$ que sería de origen antrópico. Al ser calibrada con IntCal 2020 (Hogg et al. 2020), esta fecha cae en un rango de 1732-1889 años cal. AP, con una mediana de 1821 AP. Se considera que esta fecha provee la edad basal para el Componente 2 (Romero Villanueva et al. 2020b).

\begin{tabular}{c|l|l|l|c|c|c}
\hline \multirow{2}{*}{ Nivel } & \multirow{2}{*}{ Taxón } & Familia & $\begin{array}{c}\text { Parte } \\
\text { anatómica }\end{array}$ & $\begin{array}{c}\text { Frecuencia } \\
\text { absoluta }\end{array}$ & $\begin{array}{c}\text { Frecuencia } \\
\text { relativa }\end{array}$ & $\begin{array}{c}\text { Cantidad } \\
\text { por } \mathbf{c m}^{3}\end{array}$ \\
\hline \multirow{2}{*}{1} & \multirow{2}{*}{ Sarcomphalus mistol } & \multirow{2}{*}{ Rhamnaceae } & Endocarpo & 39 & $54,20 \%$ & 0,0078 \\
\cline { 5 - 7 } & & Semilla & 1 & $1,40 \%$ & 0,0002 \\
\hline 2 & Sarcomphalus mistol & Rhamnaceae & Endocarpo & 8 & $11,10 \%$ & 0,0016 \\
\hline \multirow{2}{*}{3} & Sarcomphalus mistol & Rhamnaceae & Endocarpo & 19 & $26,40 \%$ & 0,0038 \\
\cline { 2 - 7 } & Schinus polygamus & Anacardiaceae & Endocarpo & 1 & $1,40 \%$ & 0,0002 \\
\hline 4 & Sarcomphalus mistol & Rhamnaceae & Endocarpo & 1 & $1,40 \%$ & 0,0038 \\
\hline 5 & Sarcomphalus mistol & Rhamnaceae & Semilla & 1 & $1,40 \%$ & 0,0002 \\
\hline 6 & Sarcomphalus mistol & Rhamnaceae & Semilla & 1 & $1,40 \%$ & 0,0002 \\
\hline 7 & S/M & S/M & S/M & 0 & $0 \%$ & 0 \\
\hline 8 & Sarcomphalus mistol & Rhamnaceae & Semilla & 1 & $1,40 \%$ & 0,0002 \\
\hline 9 & S/M & S/M & S/M & 0 & $0 \%$ & 0 \\
\hline 10 & S/M & S/M & S/M & 0 & $0 \%$ & 0 \\
\hline 11 & S/M & S/M & S/M & 0 & $0 \%$ & 0 \\
\hline 12 & S/M & S/M & S/M & 0 & $0 \%$ & 0 \\
\hline & Total & & 72 & $100 \%$ & \\
& & & & & \\
\hline
\end{tabular}

Tabla 2. Frecuencia de macrorrestos vegetales en el sitio arqueológico Cueva Yagui.

Referencias: S/M: Sin Macrorrestos.

Los macrorrestos recuperados en excavación comprenden 72 especímenes provenientes de 12 muestras de flotación (Tabla 2). La mayoría estaban fragmentados (ca. $80 \%, \mathrm{n}=59)$. Sólo algunos de ellos se encontraron enteros $(\mathrm{n}=$ $14)$, de los cuales varios presentaban solo una muesca $(n=11)$ mientras que los tres restantes no poseían ninguna marca de fragmentación. El estado de preservación en su totalidad es seco. La muestra evaluada está conformada por frutos (endocarpos), semillas y fragmentos de madera no identificada. Dentro del total del material analizado se reconocieron dos especies: Sarcomphalus mistol (Griseb.) Hauenschild (98,6 \% de la muestra) y Schinus polygamus (Cav.) Cabr. Asimismo, el $94 \%(n=67)$ de los especímenes procede de los niveles 1, 2 y 3 por 
lo cual, como se ha indicado arriba, se puede asignar una cronología correspondiente a los últimos 1800 años calendáricos a la mayor parte del conjunto.

Descripción de los taxones recuperados

Familia Rhamnaceae: Sarcomphalus mistol. Conocida de manera popular como mistol, siendo la única especie del género en Argentina, está representado por 67 endocarpos (94,4\% del total de la muestra) presentes en los niveles estratificados 1, 2, 3 y 4 (Figura 4a) y 4 semillas (5,6\%) distribuidas en los niveles 1, 5, 6 y 8 (Figura 4b). Los caracteres cualitativos muestran endocarpos de consistencia leñosa, secos, de color marrón oscuro, de superficie lisa, sin ornamentación y de forma elipsoide. En la muestra que estaba fragmentada se observó en su anatomía interna estructuras uniloculares y biloculares. Las dimensiones varían entre $0,8-0,5 \mathrm{~mm}$ de longitud, y 0,6 - $1 \mathrm{~mm}$ de latitud.

Familia Anacardiaceae: Schinus polygamus denominada popularmente como molle. El único endocarpo de este taxón (1,4 \% del total de la muestra) se recuperó en el nivel 3 en estado de preservación seco (Figura 4c). Sus caracteres diagnósticos corresponden a un endocarpo ovoideo, de consistencia leñosa y con una superficie marcada por estrías. Las dimensiones son $0,65 \mathrm{~mm}$ de longitud y $0,4 \mathrm{~mm}$ de latitud.
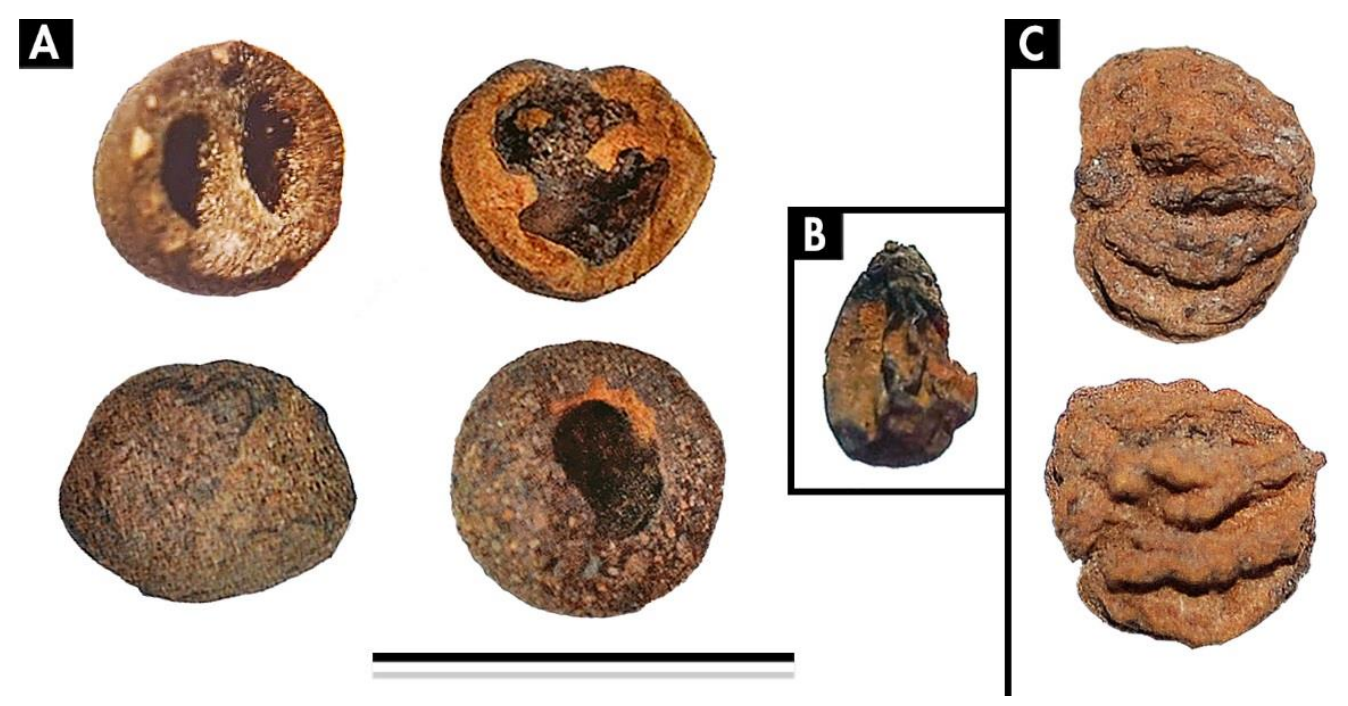

Figura 4. Macrorrestos recuperados en Cueva Yagui. a) Endocarpos de Sarcomphalus mistol; b) Semilla de Sarcomphalus mistol; c) Endocarpos de Schinus polygamus.

\section{Discusión}

La secuencia de la cuadrícula C1 en Cueva Yagui contiene dos ventanas temporales a los períodos ca. 8500-6000 años cal AP (Componente 1) y los últimos 1800 años (Componente 2), separadas por una discordancia erosiva que resume aproximadamente 4000 años calendáricos (Romero Villanueva et al. 2020b). El 94 \% (n 
=67) del registro arqueobotánico se registra en los primeros tres niveles artificiales de extracción, englobados en el Componente 2. La escasez de carporrestos en los niveles asignados al Componente 1 puede responder a la conservación diferencial entre estos dos períodos de tiempo, algo que se ve respaldado por observaciones sobre la preservación ósea en ambos componentes (Romero Villanueva et al. 2020b). No obstante, se analizaron muestras de sendas matrices sedimentarias a fin de evaluar si las características del suelo podrían ser la causante de la no preservación de los restos vegetales. Los resultados muestran un alto contenido de nitrógeno, potasio, fósforo, calcio y azufre (Sánchez Campóo 2019). Esta situación manifiesta que los materiales orgánicos, como los restos de plantas, no son factibles de conservarse en un suelo con altos niveles de nitrógeno y fósforo principalmente. Sin embargo, la consistencia leñosa de los endocarpos de mistol, como así también el de molle, presentaron un estado de preservación bueno, por lo que el suelo no habría sido la razón por la cual no se conservasen éste y otros tipos de restos con consistencia similar al mistol, como el algarrobo. En principio, era esperable que en Cueva Yagui se hubiera explotado el algarrobo, dada su presencia a nivel local, y su abundancia desde el Holoceno temprano en Cueva Huenul 1 ubicado a ca. $6 \mathrm{~km}$ de Cueva Yagui (Llano et al. 2019). Asimismo, ocupa las primeras posiciones en el ranking de recursos vegetales de la zona (Llano y Ugan 2010). Por lo tanto, a partir de las consideraciones tafonómicas y el tipo de registro presente en otros sitios, por el momento se propone una explicación conductual para dar cuenta de la ausencia de algarrobo como de la presencia extra local de mistol en Cueva Yagui. A continuación, centramos la discusión sobre el uso de recursos vegetales en el sitio dentro del marco temporal del Holoceno tardío.

\section{Aprovechamiento y traslado de mistol en Cueva Yagui}

El registro analizado en Cueva Yagui resulta notorio a nivel regional y, en particular, dentro de la provincia del Neuquén, por diversas cuestiones. En primer lugar, un total de 71 especímenes se asignan a mistol (Sarcomphalus mistol). Distintos autores coinciden en que la distribución de esta especie no incluye la zona en donde se emplaza el sitio ni espacios cercanos (Tortosa y Novara 1992). Así, estaría disponible en la zona centro-norte de Argentina y en otros países como Paraguay y Brasil (Cusato y Tortosa 2013), correspondiendo a un ambiente fitogeográfico chaqueño (Figura 5). Se puede estimar que, en la actualidad, el punto de disponibilidad más cercano a nuestra región de estudio estaría a $c a .670 \mathrm{~km}$. Esta distancia excede toda la información conocida en escala etnográfica sobre la amplitud espacial de los rangos de acción de grupos móviles (Binford 2001; Kelly 2013; Marlowe 2010). 


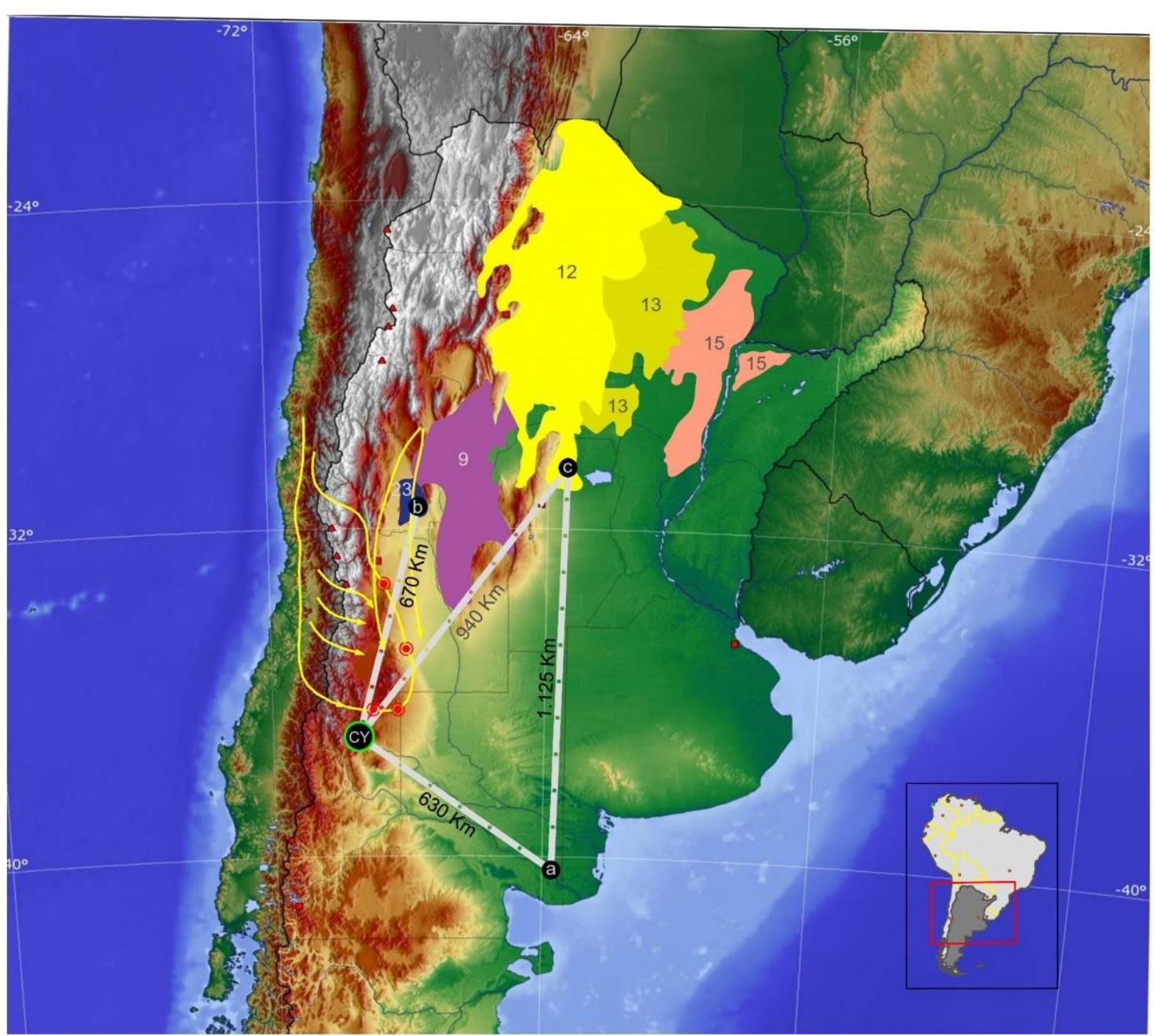

Figura 5. Distancias en $\mathrm{km}$ del aprovisionamiento de mistol a Cueva Yagui. Provincia

Fitogeográfica Chaqueña, los números 9-12-13-15 hacen referencia a las unidades vegetacionales en las que se desarrolla el mistol, el número 23 corresponde a la Provincia

Fitogeográfica del Monte (Oyarzabal et al. 2018). a) corresponde al sitio arqueológico La Angostura 1 (Capparelli y Prates 2010), b) Valle Fértil: Sitios Las Quinas (Gambier 2002) y Sitio

Las Tumanas (Cahiza 2007); c) Sitios arqueológicos de las Sierras del Norte de Córdoba (Recalde y López 2017). Línea amarilla hace referencia al intercambio cultural propuesto por Lagiglia (2009).

Cabe destacar que, con anterioridad a esta publicación, se conocía un único registro de mistol en Patagonia. El hallazgo procede del sitio Angostura 1, ubicado en la cuenca inferior del río Negro (provincia de Río Negro) (Figura 5). Haciendo a un lado las estructuras leñosas, en un conjunto dominado por Prosopis, Capparelli y Prates (2010) identificaron un macrorresto asignado a Sarcomphalus mistol asociado a un contexto cronológico de ca. 900 años AP. Los autores proponen que su presencia en este sitio de actividades múltiples, interpretado como una base residencial de grupos cazadores-recolectores, sería producto del transporte o el intercambio desde zonas de crecimiento natural.

Por su parte, el mistol es más frecuente en el registro arqueobotánico del NOA, centro-oeste y centro de Argentina. Así, se cuenta con evidencia de carozos de mistol en el registro arqueobotánico de la provincia de Catamarca en el sitio El Shincal 
(Capparelli 2009), de San Juan como Cerro Negro y alero Las Quinas (Gambier 2002). En la misma provincia, puntualmente en el Alero Las Tumanas que se emplaza en la Sierra de Valle Fértil, se halló un fragmento de raquis de Zea mays, algunos frutos de mistol y algarrobo (Prosopis sp.) (Cahiza et al. 2012). Al igual que Capparelli y Prates (2010), Gambier (2002) explica la presencia de esta especie a partir del traslado o intercambio desde zonas con flora chaqueña. Esta zona de San Juan es de especial interés dado que relevamientos actuales en el área protegida de la Reserva de Uso Múltiple Valle Fértil permitieron identificar el mistol entre las especies arbóreas presentes (Márquez 1999). Siguiendo la fitogeografía propuesta por Oyarzabal y colegas (2018) se correspondería con la Provincia fitogeográfica del Monte (Figura 5, número 23). Esto denota la presencia de este taxón en el área de los sitios arqueológicos analizados por los autores.

En el centro de Argentina se cuenta con un patrón de uso de mistol y molle representados en una alta frecuencia de individuos en el total de las muestras analizadas en múltiples sitios serranos de la provincia de Córdoba (López 2017; Medina y López 2007; Recalde y López 2017). Estos autores resaltan que, por un lado, ambas especies cuentan con ejemplares con signos que se interpretan como resultado de un guardado prolongado o almacenamiento (Recalde y López 2017). En el caso del mistol, estos signos remiten, no sólo a endocarpos limpios sino también con rasgos de haber sido secados. Por otro lado, la baja frecuencia de algarrobo es considerada como una posible sobreestima de este recurso, lo que alerta sobre la necesidad de efectuar una evaluación más exhaustiva de la ecología de la planta (López 2017). No obstante, Capparelli (2021) considera que el algarrobo es uno de los recursos más utilizados como alimento humano, donde las prácticas destinadas a facilitar el acceso a cantidades crecientes de nutrientes, llevó a estrategias de procesamiento que pudieron haber asegurado una digestión adecuada de las vainas. Esto habla de diferentes modos de preservación en las muestras arqueológicas. Por lo antedicho, en el sitio Cueva Yagui habría que evaluar otros medios que evidencien un estado de preservación diferente al macrorresto seco, como así también las formas de procesamiento del que fueron objeto, dejando abiertas otras posibilidades que incluyan el algarrobo para ser testeadas a futuro.

En relación con los usos registrados del mistol, esta especie es valiosa desde el punto de vista alimenticio. Los frutos que se encuentran disponibles en primavera son un buen forraje para la hacienda y muy apreciados para la alimentación humana (Biurrum et al. 2007). Se consumen frescos o secados al sol como pasas, se adicionan a la harina del algarrobo para elaborar patay, bolanchaos y hacer arrope. Fermentándolos se obtiene la aloja y, a partir de su destilado, el aguardiente de mistol. En la medicina casera se reporta su uso como febrífugo, hepatoprotectores (Hieronymus 1882) y para tratar enfermedades respiratorias (Tortosa y Novara 1992). Marconetto y Mafferra (2016) destacan el uso de mistol como leña junto con Prosopis y Geoffroea. 
En línea con las interpretaciones de otros colegas, dada la distribución actual del mistol, se propone que la presencia del mismo en Cueva Yagui fue por transporte o intercambio desde el centro-oeste de Argentina hasta el norte del Neuquén (ca. paralelo $30^{\circ}$ ), donde crece espontáneamente (Figura 5). Sin embargo, se considera que sus potenciales usos económicos no proveen una explicación suficiente para justificar su transporte en una distancia como la aquí registrada. Si se toma en cuenta que los endocarpos recuperados proceden de los primeros tres niveles artificiales de extracción $(0-30 \mathrm{~cm})$, es plausible sugerir una cierta diacronía en su depositación. A futuro, se realizarán fechados directos sobre esos vestigios que permitirán evaluar esta sugerencia sobre una base temporal más precisa.

\section{La ausencia de recursos silvestres locales en Cueva Yagui}

Sumado a la abundancia de un taxón no local (mistol), el registro arqueobotánico de Cueva Yagui también resulta anómalo por la escasa presencia de taxones locales, altamente productivos e inmediatamente disponibles en la actualidad en el entorno del sitio como molle (Schinus spp.) (Llano et al. 2019; Llano y Barberena 2013). Sobre esta base, el algarrobo (Prosopis spp.) sería una de las especies con mayor potencial de registrarse en la cueva. En efecto, esta expectativa sí se verifica en el sitio cercano de Cueva Huenul 1 (Llano y Barberena 2013; Llano et al. 2019Sosa 2016). De esta manera, el registro arqueobotánico replica las divergencias observadas en otras líneas de evidencia documentadas en ambos sitios de la LBB, como el arte rupestre y la tecnología cerámica, que sugieren historias ocupacionales con usos humanos diversos para estos emplazamientos cercanos que habrían sido utilizados en forma complementaria por los grupos humanos de la región en el marco de sus rangos de acción (Romero Villanueva 2019; Romero Villanueva et al. 2020b; Rughini et al. 2020).

A nivel regional, los registros del fruto de molle se encuentran citados en numerosos sitios arqueológicos del sur de Mendoza, región colindante con el área bajo estudio (Durán 2004; Gambier 1980; Hernández et al. 1999; Llano y Andreoni 2012; Llano y Neme 2012; Otaola y Llano 2015). La alta frecuencia de este macrorresto confirma su importancia regional entre los grupos humanos del pasado. En relación con los usos de esta especie se reporta como alimenticia y medicinal (diurética) aunque, en dosis altas, puede ser tóxica (Bermejo y Pasetti 1985). Los endocarpos de Schinus habrían tenido un importante papel en la dieta humana siendo el segundo taxón con mayor retorno energético (Llano y Ugan 2010). Otro uso dado a esta especie es la de combustible ya que su madera se distingue por su dureza y alto contenido en resina. Gracias a estas propiedades, posee una alta potencia calorífica, parecida a la madera del algarrobo (Prosopis spp.). Las hojas, ramas, corteza y raíces se utilizan para teñir tejidos de algodón de un color amarillo pálido y verde (Padilla y Vásquez 1985). De la corteza se extraen taninos y aceites útiles para producir un poderoso desinfectante de múltiples usos y para combatir muchos insectos que atacan al ganado (Hoyos 1990). 
Dada la importancia del algarrobo y el molle para los grupos humanos del norte del Neuquén y regiones cercanas, sumado a que ambas especies están -y habrían estado- disponibles en el entorno inmediato de Cueva Yagui, la escasa presencia de taxones vegetales silvestres locales es particularmente llamativa en el Componente (2) asignado al Holoceno tardío. Una inferencia sería su destrucción post-depositacional, que es una posibilidad que no puede ser descartada. Sin embargo, como se mencionó más arriba, los endocarpos de mistol, que tienen un potencial de preservación comparable al de estos taxones, se encuentran en muy buen estado de preservación en los niveles 1 a 3, al igual que múltiples evidencias orgánicas recuperadas en la excavación (Romero Villanueva et al. 2020b). La falta de aprovechamiento de los taxones referidos resulta aún más extraña si se contempla que las demás líneas de evidencia registradas en el sitio indican que fue ocupado en forma redundante e intensa para múltiples actividades (Fernández et al. 2017; Romero Villanueva 2019; Romero Villanueva et al. 2020b). Entre estas evidencias se cuenta con la segunda concentración de motivos rupestres más grande (180 motivos) y la mayor abundancia de restos cerámicos (67 tiestos) de la región bajo estudio, además de una importante abundancia de instrumentos líticos como manos de moler y la representación de variados grupos de obsidiana (Romero Villanueva et al. 2020b).

\section{Consideraciones finales}

En síntesis, el registro arqueobotánico de Cueva Yagui llama la atención por reflejar el uso predominante de una planta alóctona disponible a gran distancia (mistol) frente a un escaso uso de recursos localmente accesibles (por ejemplo, el algarrobo). Asimismo, la disponibilidad de ambas especies en temporada estival puede sugerir el uso del sitio durante esta estación. Sin embargo, dada su altitud, este lugar podría sostener ocupaciones durante todo el año ya que se encuentra varios cientos de metros por debajo del límite de estacionalidad (ca. 1800 m s.n.m.) establecido a partir de modelos biogeográficos (Rughini et al. 2020). En este sentido, no se descarta la posibilidad de que los frutos de mistol hayan sido adquiridos durante otras estaciones y procesados y/o consumidos meses después, dadas las sugerencias de almacenamiento propuestas para el uso de esta especie en otras zonas de Argentina (ver Recalde y López 2017).

Sin dudas, uno de los resultados más llamativos de este trabajo consistió en identificar la presencia en el norte del Neuquén, y en gran cantidad, de un conjunto de frutos de Sarcomphalus mistol procedentes del centro oeste argentino. A futuro, se buscará explorar en mayor detalle los potenciales mecanismos conductuales que pudieron estar involucrados en el traslado de estos recursos. Estos pueden abarcar diversas formas de movilidad (acceso directo) o intercambio, alternativas entre las cuales existe una amplia variedad intermedia generable a través de visitas $u$ otros mecanismos propios de las formaciones sociales abiertas (Borrero et al. 2011; Renfrew 1973). Por el momento, es válido pensar que, en gran medida, los grupos móviles del norte del Neuquén aprovechaban las plantas locales y regionales mientras que, 
algunos de ellos, podrían haber ampliado su escala de movilidad para conseguir bienes extra-regionales. Asimismo, su presencia en abundancia como en el caso del conjunto de mistol registrado en Cueva Yagui, podría representar un evento de intercambio, noción que abarcaría bienes que cambian de mano y se corresponde con mecanismos de reciprocidad (Marlowe 2010).

Así, este nuevo indicador se suma a otros ítems de procedencia conocida, registrados en la LBB y en otras zonas del noroeste de Patagonia, que permiten establecer vínculos entre esta macrorregión con otras ubicadas hacia el norte tales como la zona cuyana (Lema et al. 2012), hacia el este (Berón et al. 2012) y el oeste, allende la Cordillera de los Andes (Campbell et al. 2018; Hajduk et al. 2011). Esto evidencia una multidireccionalidad en los vectores geográficos de circulación humana, al menos durante el Holoceno tardío.

En un sentido más amplio, los nuevos datos obtenidos en Cueva Yagui, sumado a los ya disponibles para otros sitios de nuestra región de estudio, invitan a reflexionar sobre la necesidad de flexibilizar los modelos de aproximación al estudio de la movilidad y subsistencia de momentos tardíos en Patagonia, intentando comprender que las distintas formas de adquisición de los recursos permitieron ampliar la subsistencia junto con el uso diversificado y estacional del paisaje. De esta manera los grupos tardíos habrían conocido el retorno de cada ambiente, con momentos de dispersión y agregación de los mismos, siendo la flexibilidad uno de los rasgos definitorios. Para ahondar en estas cuestiones, dada la presencia de cerámica y manos de moler en el sitio, a futuro se prevé realizar análisis de microrrestos. Esto permitirá estimar si las formas de procesamiento de los recursos analizados pueden ser responsables de la ausencia de evidencia macro. A tal fin, la eventual presencia de restos de fitolitos y almidones adheridos nos permitirá aclarar esta cuestión.

En términos metodológicos, interesa destacar que el material botánico analizado se hubiera perdido de no haberse empleado la flotación como herramienta para la recuperación específica de macrorrestos vegetales.

Para finalizar, si bien de este trabajo se desprenden muchos interrogantes aún por resolver, constituye un aporte importante en cuanto a mejorar nuestro entendimiento sobre los ambientes del pasado y sus recursos a los fines de la subsistencia de los grupos móviles que habitaron el noroeste patagónico. A partir de ello, y de contemplar la extensión y regiones accedidas desde sus movimientos, reparamos en zonas alejadas de la región bajo estudio pero que ocupan un rol central para interpretar dinámicas humanas vinculadas a la circulación de personas, bienes e información en escalas amplias (Barberena et al. 2017; Berón et al. 2012, 2017). En consecuencia, resalta la importancia de estudiar la historia de esta macrorregión atendiendo a un área de extensión mayor que permitió el intercambio y explotación de especies extra regionales. 
Agradecimientos: Este artículo es el resultado de investigaciones que han recibido el financiamiento del CONICET y la Agencia Nacional de Promoción de la Ciencia y la Tecnología de Argentina mediante los Proyectos PIP 0301 (dirigido por Valeria Cortegoso) y PICT 2016-0062. Nuestro trabajo ha sido posible gracias al apoyo de las comunidades de Barrancas y Buta Ranquil (Provincia del Neuquén) y a la Dirección de Patrimonio Cultural de la Provincia del Neuquén (Carlos Cides, Claudia Della Negra y Pablo Azar). Finalmente, agradecemos a Agustina Rughini y Raven Garvey por su colaboración durante la excavación y el registro del arte rupestre de Cueva Yagui.

\section{Notas}

1 Sarcomphalus mistol es el nombre aceptado recientemente para Ziziphus mistol Griseb., que pasó a la categoría de sinónimo (Zuloaga y Morrone 2009).

\section{Bibliografía citada}

Barberena, R., G. Romero Villanueva, G. Lucero, M. V. Fernández, A. A. Rughini y P. Sosa

2017 Espacios internodales en Patagonia septentrional: biogeografía, información y mecanismos sociales de interacción. Estudios Atacameños 56: 57-75.

Belmar, C., C. Méndez y O. Reyes

2017 Hunter-gatherer plant resource use during the Holocene in central western Patagonia (Aisén, Chile, South America). Vegetation History and Archaeobotany 26(6): 607-625.

Bermejo, J. y F. Pasetti

1985 El árbol en apoyo de la agricultura; sistemas agroforestales en la Sierra Peruana (No. 12968). Instituto Nacional Forestal y de la Fauna, FAO, Lima.

Berón, M., R. Mera y D. Munita

2012 Traspasando barreras, interacciones sociales y conflicto allende la cordillera andina. Actas del XVIII Congreso Nacional de Arqueología Chilena, pp. 351-357. Sociedad Chilena de Arqueología, Santiago de Chile.

Berón, M. A., A. Di Biase, M. G. Musaubach y F. Páez

2017 Enclaves y espacios internodales en la dinámica de poblaciones en el wallmapu. Aportes desde la arqueología pampeana. Estudios Atacameños 56: 253-272.

Binford, L.

2001 Constructing Frames of Reference: An analytical method for archeological theory using hunter-gatherer and environmental data sets. 
Biurrum, E., L. Galetto, A. M. R. Anton y F. Biurrum

2007 Plantas silvestres comestibles utilizadas en poblaciones rurales de la Provincia de La Rioja (Argentina). Kurtziana 33(1): 121-140.

Borrero, L., F. Martin y R. Barberena

2011 Visits, "Fuegians," and Information Networks. The Role of Information in HunterGatherer Band Level Societies (ed. por W. Lovis, R. Whallon y R. Hitchcock), pp. 249-296. Cotsen Institute of Archaeology Press, University of California, Los Ángeles.

Cahiza, P. A.

2007 Las Sociedades Formativas tardías de Valle Fértil, San Juan. Comechingonia. Revista de Arqueología 10: 79-94.

Cahiza, P. A., J. P. Aguilar y J. García Llorca

2012 Tecnología ósea del alero Las Tumanas (LT1), Valle Fértil, San Juan. Comechingonia. Revista de Arqueología 16(2): 75-91.

Campbell, R., C. Roa y F. Santana-Sagredo.

2018 Más sureño que los porotos: primeros fechados 14C AMS para el sitio Cueva de Los Catalanes. Boletín Sociedad Chilena Arqueología 48: 85-89.

Capparelli, A.

2009 Intra-site comparison of the archaeobotanical evidence of El Shincal: implications about the inka economy. La alimentación en la América precolombina y colonial: una aproximación interdisciplinaria, 7, 113.

2021. Ethnobotany of Prosopis spp., past evidence of the fruit use and experimental archaeology applied to the interpretation of ancient food processing. (ed. por Puppo M.C. \& Peter Felker). Elsevier

Capparelli, A. y L. Prates

2010 Identificación especifica de frutos de algarrobo (Prosopis spp., Fabaceae) y Mistol (Ziziphus mistol Griseb, Rhamnaceae) en un sitio arqueológico de Patagonia. Tradiciones y transformaciones en Etnobotánica (ed. por M. L. Pochettino, A. H. Ladio y P. M. Arenas), pp. 13-19. CYTED Programa Iberoamericano Ciencia y Tecnología para el Desarrollo, Argentina.

Carreras, C. y M. Nieto

1996 Análisis de muestras de Austrocactus aif. Austrocacius heriinii procedentes de la cueva Epullán Grande (Provincia del Neuquén). Prohistoria 2: 279-282.

Caruso Fermé, L.

2018 Methods of acquisition and use of firewood among hunter-gatherer groups in Patagonia (Argentina) during the Holocene. Vegetation History and Archaeobotany 28(4): 465-479. 


\section{Ciampagna ML.}

2015 Estudio de la interacción de los grupos cazadores recolectores que habitaron la costa Norte de Santa Cruz y las plantas silvestres: recolección y gestión. Tesis Doctoral Inedita. FCNyM, UNLP.

\section{Ciampagna, M. L. y E. Mange}

2017 Primeros estudios arqueobotánicos del sitio Cueva Epullán Chica (Depto. Collón Curá, Pcia. del Neuquén). Antilatinoamérica: una mirada desde el presente hacia el pasado. XI Coloquio Binacional Argentino-Peruano (comp. por M. T. de Haro et al.), pp. 167-183. Ashpa Ediciones, Buenos Aires.

Crittenden, A. N. y S. L. Schnorr

2017 Current views on hunter-gatherer nutrition and the evolution of the human diet. American Journal of Physical Anthropology 162: 84-109.

Crivelli Montero, E., U. Pardiñas, M. Fernández, M. Bogazzi, A. Chauvin, V. Fernández y M. Lezcano

1996 La Cueva Epullán Grande (Provincia del Neuquén, Argentina). Informe de avance. Præhistoria 2: 185-265.

Cúneo, E. M., A. Hajduk, P. S. Novellino y P. F. Azar

2016 Rescate de un cementerio de cazadores-recolectores prehispánicos: sitio Loma de la Lata (provincia del Neuquén, República Argentina). Intersecciones en Antropología 17(3): 315-325.

Cusato, L. I. y R. D. Tortosa

2013 Rhamnaceae. Flora del Paraguay 44 (ed. por L. Ramella y P. Perret). Conservatoire et Jardin botaniques de la Ville de Genève.

Della Negra, C. E. y P. S. Novellino

2005 "Aquihuecó": un cementerio arqueológico, en el Norte de la Patagonia, Valle del Curi Leuvú-Neuquén, Argentina. Magallania 33(2): 165-172.

Della Negra, C., P. S. Novellino, F. Gordón, R. Vázquez, M. Béguelin, P. González y V. Bernal

2014 Áreas de entierro en cazadores-recolectores del Noroeste de Patagonia: sitio Hermanos Lazcano (Chos Malal, Neuquén). RUNA 35(2): 5-19.

Della Negra, C., P. S. Novellino, S. I. Pérez, A. Hajduk y V. Bernal 2009 Investigaciones arqueológicas y bioarqueológicas en el sitio Aquihuecó (Norpatagonia): nuevos resultados. Arqueología de la Patagonia. Una mirada desde el último confín (ed. por M. Salemme, F. Santiago, M. Álvarez, E. Piana, M. Vázquez y E. Mansur), pp. 669-676. Utopías, Ushuaia. 
Durán, V.

2004 Poblaciones Indígenas de Malargüe. Su Arqueología e Historia. Ceider, Serie de Libros No 1 . Facultad de Filosofía y Letras, Universidad Nacional de Cuyo, Mendoza.

Esau, K.

1972 Anatomía vegetal. Trad. de J. Pons R. Barcelona, Ediciones Omega, Madrid.

Fernández, C. y H. Panarello

2001 Cazadores recolectores del Holoceno Medio y Superior de la Cueva Haichol, región cordillerana central del Neuquén, República Argentina. Relaciones de la Sociedad Argentina de Antropología 26: 9-30.

Fernández, M. V., R. Barberena, M. Giesso, A. A. Rughini, V. Cortegoso, M. D. Glascock, V. Durán, G. Romero Villanueva, K. Borrazzo, G. Lucero, R. Garvey y B. L. MacDonald

2017 Obsidian geochemistry, geoarchaeology, and lithic technology in northwestern Patagonia (Argentina). Journal of Archaeological Science: Reports 13: 372-381.

Figueroa, G. y M. Dantas

2006 Recolección, procesamiento y consumo de frutos silvestres en el noroeste semiárido argentino. Casos actuales con implicancias arqueológicas. La Zaranda de Ideas 2: 35-50.

Gambier, M.

1980 Excavaciones en la Gruta de El Manzano, Río Grande-Mendoza. Boletín del Museo de Ciencias Naturales y Antropológicas Juan Cornelio Moyano 1:45-55. Mendoza.

2002 Las Quinas: un nuevo sitio de la cultura de La Aguada en San Juan. Estudios Atacameños 24: 83-88.

Gordón, F., R. Barberena y V. Bernal (editores)

2017 El poblamiento del norte del y perspectivas. Estado actual del conocimiento humano Neuquén. Aspha Ediciones, Buenos Aires.

Hajduk, A., A. M. Albornoz y M. J. Lezcano

2011 Espacio, cultura y tiempo: el corredor bioceánico desde la perspectiva arqueológica. Cultura y espacio. Araucanía-Norpatagonia (ed. por P. N. Floria y W. Delrio), pp. 262-292. Universidad Nacional de Río Negro, Bariloche.

Hernández, A., H. Lagiglia y A. Gil

1999 El registro arqueobotánico en el Sitio Agua de los Caballos-1 (San Rafael, Mendoza). Anales de Arqueología y Etnología 54-55: 181-203. 
Hieronymus, G.

1882 Plantae diaphoricae florae Argentinae: ó, Revista sistemática de las plantas medicinales, alimenticias ó de alguna otra utilidad y de las venenosas, qùe son indígenas de la República Argentina. G. Kraft, Buenos Aires.

Hogg, A. G., T. J. Heaton, Q. Hua, J. G. Palmer, C. SM. Turney, J. Southon, A. Bayliss, P. G. Blackwell, G. Boswijk, C. Bronk Ramsey, C. Pearson, F. Petchey. P. Reimer, R. Reimer y L. Wacker

2020 SHCal20 Southern Hemisphere Calibration, 0-55,000 Years Cal BP. Radiocarbon 62(4): 759-778.

Hoyos, J. F.

1990 Los Árboles de Caracas. Monografía No. 24. Sociedad de Ciencias Naturales La Salle, Caracas.

Kelly, R.

2013 The Lifeways of Hunter-Gatherers: The Foraging Spectrum. Cambridge University Press, Cambridge.

Lagiglia, $\mathrm{H}$.

1999 Los Orígenes de la Agricultura en Argentina. Museo Municipal de Historia Natural, San Rafael.

2009. Indicadores arqueológicos de movilidad cultural en el centro-oeste argentino y aledaños. Sociedades de paisajes áridos y semiáridos 1, 15-43.

Lahr, M. M. y R. Foley

1998 Towards a Theory of Modern Human Origins: Geography, Demography, and Diversity in Recent Human Evolution. Yearbook of Physical Anthropology 41: 137-176.

Lema, V. S., C. Della Negra y V. Bernal

2012 Explotación de recursos vegetales silvestres y domesticados en Neuquén: implicancias del hallazgo de restos de maíz y algarrobo en artefactos de molienda del Holoceno tardío. Magallania 40(1): 229-247.

Llano, C.

2015 On optimal use of a patchy environment: archaeobotany in the Argentinean Andes (Argentina). Journal of Archaeological Science 54: 182-192.

Llano, C. y A. Ugan

2010 Rendimiento Económico de plantas silvestres del sur de Mendoza: valores nutricionales, costos de manejo e interpretación del registro arqueológico. Tradiciones y transformaciones en Etnobotánica (ed. por M. L. Pochettino, A. H. Ladio y P. M. Arenas), pp. 44-48. CYTED Programa Iberoamericano Ciencia y Tecnología para el Desarrollo, Argentina. 
Llano, C. y D. Andreoni

2012 Caracterización espacial y temporal en el uso de los recursos vegetales entre los grupos cazadores-recolectores del sur mendocino durante el Holoceno. Paleoecología humana en el sur de Mendoza: perspectivas arqueológicas (ed. por G. Neme y A. Gil), pp. 5784. Sociedad Argentina de Antropología, Buenos Aires.

Llano, C. y G. Neme

2012 El registro arqueobotánico en el valle del Salado, Mendoza: problemas tafonómicos y explotación humana. Chungará Revista de Antropología Chilena 44(2): 269285.

Llano, C. y R. Barberena

2013 Explotación de especies vegetales en la Patagonia septentrional: El registro arqueobotánico de Cueva Huenul 1 (Provincia de Neuquén, Argentina). Darwiniana, nueva serie 1(1): 5-19.

Llano, C., P. Sosa, C. Sánchez Campóo y R. Barberena

2019 Arqueobotánica de Cueva Huenul 1 (Neuquén, Argentina): selección y procesamiento de especies vegetales. InterSecciones en Antropología 20(2): 211-223.

Llano, C., M. E. de Porras, R. Barberena, A. Timpson, M. O. Beltrame y E. Marsh

2020 Human resilience to Holocene climate changes inferred from rodent middens in drylands of northwestern Patagonia (Argentina). Paleogeography, Paleoclimatology, Paleoecology 557, 109894.

López, M. L.

2017 Archaeobotany in central Argentina: macro and microscopic remains at several archaeological sites from early Late Holocene to early colonial times (3,000-250 BP). Vegetation history and archaeobotany 27(1): 219-228.

Marconetto, M. B. y L. E. Mafferra

2016 Todos los fuegos, el fuego: discusión en torno a las categorías modernas en la interpretación de registros antracológicos en contextos prehispánicos y coloniales. Cadernos do LEPAARQ XIII (25): 460-483.

Marlowe, F. W.

2010 The Hadza: Hunter-Gatherers of Tanzania. University of California Press, Berkeley. Márquez, J.

1999 Las áreas protegidas de la provincia de San Juan. Multequina 8: 1-10.

Martin, A. C. y W. D. Barkley

1973 Seed Identification Manual. University of California Press, California. 
Medina, M. y L. López

2007 Arqueobotánica del Sitio Puesto La Esquina 1 (Pampa de Olaen, Córdoba): Resultados Preliminares. Actas del XVI Congreso Nacional de Arqueología Argentina. Tras las Huellas de la Materialidad. Tomo III, pp. 477-482. Universidad Nacional de Jujuy Facultad de Humanidades y Ciencias Sociales, San Salvador de Jujuy.

Musaubach, M. G. y M. A. Berón

2016 El uso de recursos vegetales entre los cazadores-recolectores de la Pampa Occidental Argentina. Latin American Antiquity 27(3): 397-413.

Otaola, C. y C. Llano

2015 Consumo de vegetales y animales en el sur de Mendoza: el caso del sitio Cueva Palulo. Intersecciones en Antropología 16(1): 221-235.

Oyarzábal, M., J. Clavijo, L. Oakley, F. Biganzoll, P. Tognetti, P., I. Barberis, H. Maturo, M. Aragón, P. Campanello, D. Prado, M. Oesterheld y R. Leon

2018 Unidades de vegetación de la Argentina. Ecología Austral 28(1): 40-63.

Padilla, M. S. y B. Vásquez

1985 Experiencias en la producción de plantones en vivero para algunas especies nativas. Cicafor $\mathrm{N}^{\circ}$ 5-85.

Pallo, M. C. y L. A. Borrero

2015 ¿Intercambio o movilidad?: una evaluación sobre el uso de escalas de análisis espaciales y curvas de declinación en Patagonia centro-meridional (Argentina). Latin American Antiquity 26(3): 287-303.

Pearsall, D. M.

2000 Paleoethnobotany: a handbook of procedures. Academic Press, San Diego.

Pérez de Micou, C.

1988-1990 Estudio de una pieza de cestería. Arqueología de la cueva Haichol. Anales de Arqueología y Etnología 43-45(2): 327-330.

Recalde, A. y L. López

2017 Las sociedades prehispánicas tardías en la región septentrional del centro de Argentina (Sierras del Norte, Córdoba). Avances a su conocimiento desde los recursos vegetales. Chungará, Revista de Antropología Chilena 49(4): 1-16.

Renfrew, J. M.

1973 Paleoethnobotany. The prehistoric food plants of Near east and Europe. Columbia University Press, New York. 
Rivera, S. M. y V. M. Fernández

1997-1998 Identificación de material leñoso y otros vestigios macrovegetales arqueológicos de la cueva Epullán Grande, provincia de Neuquén. Algunos aspectos metodológicos y culturales. Paleoetnologica 9: 33-48.

Roa, C., D. Bustos, H. Ramírez y R. Campbell

2018 Entre la pampa y el pacífico sur. Evaluando la dispersión más austral de cultígenos en el cono sur americano desde la evidencia arqueobotánica y radiométrica de isla mocha y cueva de los catalanes (sur de Chile). Anales de Arqueología y Etnología 73(2): 189-220.

Romero Villanueva, G.

2019 Biogeografía humana y circulación de información en el norte del Neuquén. Un análisis arqueológico sobre la comunicación visual en grupos cazadores-recolectores del Noroeste de Patagonia. Tesis Doctoral. Universidad de Buenos Aires, Buenos Aires.

Romero Villanueva, G., G. Lucero y R. Barberena

2020a Andean summer-break: rock art insights on information networks and social interaction in a desert-highland interface in northern Patagonia (South America). Cuadernos de Arte Prehistórico. Volumen especial 1: 89-121.

Romero Villanueva, G., A. Rughini, J. Paiva, R. Garvey, A. Brera, C. Sánchez-Campoo, K. Borrazzo, C. Frigolé, A. Gasco, C. Llano, M. V. Fernández y R. Barberena 2020b Historia ocupacional y organización espacial humana en Patagonia: una discusión desde Cueva Yagui (provincia del Neuquén, Argentina). En evaluación: Chungará.

Rughini, A., G. Romero Villanueva, G. Lucero, M. Cardillo, K. Borrazzo, M. V. Fernández, A. Brera, C. Frigolé, A. Castillo, M. Vitores, C. Llano, R. Garvey y R. Barberena.

2020 Arqueología distribucional y biogeografía humana en un paisaje andinopatagónico. Latin American Antiquity 31(3): 595-614.

Sánchez Campóo, M. C.

2019 Arqueobotánica del sitio Cueva Yagui Una propuesta de investigación interdisciplinaria. Tesis de Licenciatura en Biología. Universidad del Aconcagua, Mendoza.

Sosa, P.

2016 Descifrando interacciones de cazadores-recolectores con los recursos vegetales silvestres a lo largo del Holoceno: Arqueobotánica del sitio arqueológico Cueva Huenul 1 (Neuquén, Argentina). Tesis de Licenciatura en Biología. Universidad Nacional de Cuyo, Mendoza. 
Thomas, K. D. y L. Zapata

2018 The efficiency of flotation compared with other methods for recovering assemblages of terrestrial and aquatic gastropods from archaeological deposits, with reference to the site of Pico Ramos (Basque Country, Spain). Environmental Archaeology 23(4): 378-388.

Tortosa, R. D. y L. Novara

1992 Rhamnaceae. Aportes Botánicos de Salta-Serie Flora 1(13): 1-21.

Whallon, R.

2006 Social networks and information: Non-"utilitarian" mobility among huntergatherers. Journal of Anthropological Archaeology 25: 259-270.

Wright, P. J.

2005 Flotation samples and some paleoethnobotanical implications. Journal of Archaeological Science 32(1): 19-26.

Zuloaga, F., Morrone, O., y Belgrano, M.

2009 Flora del Cono Sur. Catálogo de las Plantas Vasculares. Instituto de Botánica Darwinion, Buenos Aires. 